\title{
El ateísmo como delito extremo en las Leyes de Platón ${ }^{1}$
}

\author{
Livio Rossetti
}

$\mathrm{E}$

n el contexto del gran esfuerzo de codificación que Platón hace en las Leyes, todo el libro décimo está dedicado a la cuestión de la impiedad, y en particular al ateísmo. En su mayor parte, esta exposición particular es de orden teórico, pero una vez planteados los principios, Platón se preocupa por describir en detalle algunas medidas para la prevención y la represión del delito de ateísmo en sus diversas formas. Como veremos, su manera de concebir la represión del ateísmo destaca -entre otras razones- por el hecho de ver en ella un principio estratégico, y porque asocia a estas medidas una concepción absolutamente nueva para la época -la posibilidad de la condena a prisión. El dispositivo previsto debe además ser contextualizado, entre otras cosas, en relación con la idea de los crímenes innombrables, y el contexto no se refiere sólo a la ideología que inspira las directrices platónicas en este terreno. En consecuencia, hay bastante material para tratar de analizar estas medidas con más profundidad de lo que suele ocurrir en la literatura sobre las Leyes.

$$
* * *
$$

En primer lugar, los datos fundamentales. Cuando el anciano Platón se encontraba ya al final de su prestigiosa carrera, entre los setenta y los ochenta

\footnotetext{
${ }^{1}$ Agradezco la colaboración de Virma Donnadiéu Sánchez, quien preparó la primera traducción al español, en la que posteriormente introduje algunos cambios. He leído versiones anteriores de este texto en el Institut de Criminologie de Paris (Université Paris II) en febrero de 1997 en el marco del seminario "Les crimes innommables" organizado por el Equipe Internationale Interdisciplinaire de Philosophie Pénale y en particular por el doctor Stamatios Tzitzis (Directeur de recherche del CNRS), y después en la Facultad de Filosofía y Letras y en el Instituto de Investigaciones Filosóficas de la UNAM en abril de 1997. El debate que tuvo lugar en ambas circunstancias fue iluminador, y lamento no poder dar cuenta de los aportes individuales.
} 
años de edad, su ocupación principal fue llevar a término una obra "mamut", superior en amplitud a la República: las Leyes. En ese entonces, su Academia marchaba y tal vez le planteaba problemas. Tuvo, además, la oportunidad de realizar una conferencia pública: "Sobre el bien". Pero es indiscutible que debió concentrar la mayor parte de sus energías intelectuales en la redacción de este gran libro.

Es casi seguro que en ese momento el filósofo se beneficiaba de la ayuda de un grammateus que, según leemos en un pápiro de Herculano, "escribía para él". Debe tratarse de Filipo de Opunte, quien, por un lado, dio la última mano a esta obra después de la muerte del maestro y, por otro, escribió una especie de apéndice a los Nomoi, es decir, el Epínomis. Dado que este alumno secretario era sobre todo un teólogo, es casi imposible que haya podido contribuir de manera sustancial a la afinación del verdadero código civil y penal que se esconde apenas, aquí y allá, en las Leyes. No obstante, hay que considerar que el excurso acerca del alma del mundo, medular en el libro X, concuerda muy bien con la teología astral del Epínomis (como también con teorías semejantes de otros alumnos del mismo periodo, como Jenócrates y Heráclides del Ponto) sin que por ello haya verdadera discontinuidad entre dicho excurso y el contexto. De hecho, es muy probable que el anciano maestro haya podido compartir con ellos aún algunas teorías de este género.

Pasemos ahora a echar un vistazo al conjunto de las Leyes. Su proyecto de fundar una nueva colonia en la isla de Creta (proyecto que proviene de la ficción, y no tanto de la esperanza de concretarlo algún día) le da una excelente oportunidad para elaborar una revisión sustancial -y de gran valor- de la utopía esbozada en la República, así como para iniciar una verdadera tentativa de nueva codificación, frecuentemente articulada mediante dispositivos formales, que se clasifica en unos ciento quince tipos de crímenes $^{2}$ sabiamente agrupados (y con frecuencia analizados según las diferentes maneras de perpetrarlos), y que se integra dentro de una discusión muy rica sobre los criterios que inspiran las medidas propuestas. Tenemos allí, pues, un verdadero monumento de cultura jurídica, que se mantiene inigualado. De hecho, salvo las leyes de Gortina (mediados del siglo v antes de Cristo), la literatura jurídica griega de la época clásica no da cuenta de ninguna otra obra en la que se encuentre una codificación formal de leyes.

Del delito religioso, Platón se ocupa al final de un largo recorrido que, después de múltiples preliminares, sobre todo de orden politológico (libros I a v), se articula en un tratado sobre las instituciones civiles y militares de la

${ }^{2}$ Véase T. J. Saunders, Plato's Penal Code: tradition, controversy and reform in Greek Penology. Oxford, Universidad de Oxford, 1991. 
nueva ciudad (gran parte del libro VI), un tratado sobre la educación (final del libro VI y libro VII), un tratado sobre temas diversos como las festividades religiosas, la preparación de los reclutamientos y las competencias de los jóvenes, los concursos musicales, el casamiento, la agricultura y el comercio (libro VIII) y, finalmente, un tratado sobre el derecho penal (sacrilegio, traición, homicidio y maltratos: libro IX), después de lo cual encontramos el libro X, referente a la impiedad y al ateísmo y, a continuación, un imponente tratado de derecho civil (como diríamos nosotros: libro XI y principio del XII).

La ficción de la nueva colonia funciona pues, ante todo, como pretexto para formular una muy analítica serie de propuestas que apuntan a repensar ab imis (aunque sin mucho fantasear y sobre la base de una percepción muy clara de la realidad de su tiempo) el conjunto de la vida pública y sus reglas. Nadie duda que para ese propósito Platón pudo contar con un conocimiento detallado de las leyes y de las otras "reglas del juego" de Atenas. Dado que él apunta siempre a la reforma, se aleja frecuentemente de las reglas vigentes en su época, sobre todo cuando concibe una función estratégica de ciertos grupos de normas, a fin de racionalizar la vida comunitaria e impedir ciertos tipos de perversión que él observa en Atenas (y que deplora).

Hay, pues, dos niveles diferentes de alejamiento de las normas vigentes: en menor cantidad en materia de economía, de contratos o de agresión, y otro, mucho mayor, cuando se trata de las estructuras del poder y de la organización de los tribunales (Platón introduce, por ejemplo, una corte de segundo grado y una de tercero, lo que es extraordinariamente novedoso para su época) porque, a su manera de ver, en estos dos campos hay una debilidad inquietante de la maquinaria pública, y no sólo en su ciudad.

$* * *$

Tratemos ahora de encuadrar estas páginas en el contexto de ciertos aspectos de la costumbre (la actitud hacia el delito religioso, la actitud hacia la violencia física y hacia la pena capital, el ateísmo conocido por los griegos) así como de la organización estatal (la prisión en tanto instrumento de castigo por parte del Estado), y aún de la cultura que anima las evaluaciones del filósofo-legislador. De todo ello tendremos necesidad para poder apreciar la novedad del estudio platónico, o su arraigo en una cultura y en unos valores (en todo caso tabúes) bien establecidos.

El principio inspirador es siempre la búsqueda de un criterio de organización de la vida pública y privada que sea capaz de impedir el relajamiento de las costumbres (fenómeno que él cree constatar en la realidad de Atenas y que juzga catastrófico, o casi). Lo que destaca el proyecto de reorganización del 
Estado en las Leyes, del proyecto esbozado en la República, es lo que está detrás del conjunto de las prescripciones particulares: una verdadera estrategia de promoción de la interiorización de las reglas y los valores, y por tanto, de una conducta correcta por parte de la mayoría de los habitantes.

Esta vez Platón no se contenta con esperar a que un buen filósofo o un buen príncipe tome el poder y sepa de antemano cómo reorganizar y dirigir el Estado, ni se contenta con formular buenas leyes (a pesar de sus dudas sobre la posibilidad de que las leyes sean eficaces o que, cuando menos no sean contraproducentes). ${ }^{3}$ En contraste, ahora Platón trata de establecer un tejido de condiciones y una atmósfera o clima cultural capaz de asegurar el respeto e inclusive la interiorización de las reglas de la vida en comunidad que la ley codifica. En efecto, en las Leyes es central la búsqueda de una pluralidad de medios diferentes, cuyo conjunto debiera favorecer la interiorización de estas reglas y, en consecuencia, debiera asegurar un buen funcionamiento social, aunque hagan falta verdaderos filósofos para cumplir con las funciones de la cumbre gobernante en el Estado cretense. Veamos algunos de estos medios:

- Solemnidad de los rituales para magistrados (en el sentido de Platón, un compromiso solemne y público para cumplir las propias obligaciones debería traducirse en una interiorización del sentimiento del honor y, por lo tanto, en un compromiso para cumplir cuidadosamente una determinada función).

- Política de honores (previsión de muchas clases de sanción positiva) para el caso de buena conducta.

- Esfuerzo por hacer comprender de manera correcta el espíritu de estas reglas, así como también la obligación para los magistrados de tratar de imbuir valores positivos (sobre todo la religión en el caso de los ateos: esto lo veremos más en detalle a continuación).

${ }^{3}$ Sobre este punto se destacan las páginas de la República, libro VIII, donde se insiste mucho en la posibilidad de hacer una interpretación incorrecta de las leyes o de modificarlas como les plazca a los que tienen el poder. En el Político, Platón habla de la necesidad de leyes escritas, pero después de detenerse en los inconvenientes de la rigidez de la ley escrita (294a-296a). He tratado de analizar la evolución del pensamiento platónico sobre las leyes en algunos artículos: "Come instaurare un nuovo assetto costituzionale secondo Platone (la 'spiacevole necessità' : chi, se non il demos?)”, Gerión, III 1985, pp. 63-77; "Sui rischi di un'attitudine troppo benevola dell'interprete verso il testo: il caso del Politico", en Platón: los diálogos tardíos. Actas del Symposium Platonicum 1986, C. Eggers Lan, comp. México, UNAM, 1987; reimpreso en Sankt Augustin, Academia Verlag, 1994, pp. 9-34; "La riforma delle istituzioni tra legislazione ed educazione in Platone", en L'educazione giuridica. Modelli di legislazione e scienza della legislazio$n e$, A. Giuliani y N. Picardi, eds., t. v, vol. I. Nápoles, Edizioni Scientifiche Italiane, 1988, pp. 29-56. 
- Reconocimiento de la importancia del establecimiento de una verdadera ideología que pueda sostener adecuadamente la voluntad de apegarse a una conducta correcta.

- Sistema de control recíproco e incitación a la censura espontánea por parte de cualquier persona que observe una conducta reprochable.

- Represión sistemática de la mala conducta, sobre todo con medidas espectaculares (no necesariamente muy severas), que puedan traducirse eo ipso en lección para los otros.

- Por último, medidas profilácticas con el propósito de evitar la propagación de ideas o formas de conducta susceptibles de ser tomadas como malos ejemplos o, peor aún, que puedan traducirse en propagación de malos modelos de conducta.

Respecto de la República, hay un progreso esencial por el hecho de poner la confianza, ya no en el hombre "divino", quien sabe (o debería saber) cómo gobernar, sino en una estructuración coordenada y clarividente de casi todo elemento de la vida social, de manera que el propio ciudadano, el extranjero, la mujer, puedan concurrir al respeto efectivo (no sólo formal) de las leyes.

Una lógica de esta naturaleza nos permite desde ahora comprender cómo Platón pudo considerar al ateísmo como el peor de los crímenes. La idea consiste en que despreciar o ignorar a los dioses y, con mayor razón, negar abiertamente su existencia - pero también, detalle sorprendente, pensar que no es difícil apaciguarlos por medio de ofrendas y de ruegos- ${ }^{4}$ equivale a romper las reglas de la convivencia en el nivel simbólico, lo cual no podría sino abrir la puerta a la ruptura de las reglas también en la práctica.

La idea central es, pues, que "si Dios no existe, entonces todo está permitido". Al comienzo del libro x encontramos, en efecto, expresiones comparables al famoso concepto del personaje de Dostoyevski, sobre todo en 885b: "aquel que, de acuerdo con las leyes, piensa que los dioses existen, nunca ha perpetrado un acto impío por su propia voluntad ni pronunciado una palabra ilegal". Entre estas dos formulaciones hay evidentemente diferencias (destaca la colocación de la negación de manera diferente), pero, si para Platón la creencia religiosa y la conducta según las leyes son inseparables, en igual forma, para Raskolnikov el ateísmo es inseparable de la decisión de menospreciar una ley que está escrita en la mente de todo ciudadano (una ley interiorizada) antes de ser ley de un Estado, es decir, [que es asunto] de la ideología mucho más que del código.

Para Platón está igualmente claro que siendo el ateo, con mucha frecuencia, una persona bastante cultivada (sobre todo alimentada por cultura

${ }^{4}$ Ésta sería otra manera de confinar en un rincón a los dioses y, al margen de ciertos sacrificios, permitirse vivir como si éstos no existieran. 
astronómica de tipo jónico: $c f$. 886d, 889bc, 891c), llevar a cabo, a este respecto, una imposición sin tomarse el esfuerzo de persuadir sería, a la luz del principio de interiorización de las normas que inspira todo su proyecto, una medida insuficiente y poco funcional: sin persuasión, la persecución de los ateos podría favorecer más bien la formación de un sentimiento de opresión injustificada y podría, en consecuencia, traducirse en un refuerzo del ateísmo. Además, si la piedad sincera es inseparable del respeto de las leyes, la impiedad puede dar lugar no sólo a conductas horrendas, sino también a la combinación de ateísmo y de conducta honesta (908b-d), lo que, según Platón, sería particularmente peligroso por el hecho de no provocar efectos inmediatos y parecer inocua.

De ahí el sentido de la larga exposición, que introduce a título de preámbulo del dispositivo legal, sobre cómo podemos impugnar a los ateos del punto de vista doctrinal. Dicho preámbulo, por un lado, aclara el sentido del dispositivo y, por el otro, cumple la función de ser una reserva de argumentos para los esfuerzos por persuadir a los ateos que, como veremos, los magistrados deberán hacer en el momento oportuno.

De allí, en igual forma, la necesidad de prever medidas muy diferentes en el caso del ateo honesto y del ateo que hace proselitismo solapado (o peor que eso).

$* * *$

Vayamos, pues, al dispositivo, que es esencialmente tripartita:

Primera tipología: Platón considera, por principio de cuentas, al ateo que lo es desde el punto de vista ideológico pero que continúa apegándose a la rectitud personal, que evita mezclarse con los hombres injustos y también hacer proselitismo (Leyes x 908b). Para este tipo de personas, él formula (909a) el conjunto de prescripciones siguiente:

- Por lo menos cinco años en "centros de readaptación", en especial en el sophronisterion o "casa de reeducación”, que será un edificio situado en el centro de la ciudad, muy cerca de los otros edificios del gobierno ( $c f$. 908a).

- Aislamiento, es decir, prohibición de toda relación con los demás ciudadanos y sin que haya otro tipo de detenidos en el mismo lugar, y todo ello, a pesar de la facilidad teórica de tener contacto con los miembros de la familia o con amigos (lo cual sirve para subrayar la gravedad del delito, tanto a ellos mismos como a los demás).

- Visitas periódicas de los magistrados supremos de la colonia (los miembros del Consejo Nocturno) con la tarea de hacer exhortaciones a los detenidos y de impulsarlos a "salvar sus almas", con la tarea, pues, de hacer lo mejor 
posible por persuadirlos a abandonar estas creencias totalmente erróneas y antisociales y a recuperar la fe colectiva así como la legalidad.

- Después de este periodo, o bien se los libera o bien se los ejecuta, sea que el detenido no llegara a enmendarse, sea que haya reincidencia (suposición legal de imposibilidad de reincorporarlo algún día en la sociedad civil).

Hay que notar (regresaremos a esto) que ningún otro texto griego, anterior o posterior a las Leyes, habla de centros de readaptación previstos para largos periodos de detención.

Segunda tipología: el ateo activo y el solapado, es decir, aquel que hace proselitismo y que, para ello, pone en marcha estrategias con el fin de inducir, en forma imperceptible, a ciudadanos bien intencionados a simpatizar con el ateísmo. Para estos casos, juzgando la reglamentación establecida para los ateos honestos, hubiéramos podido pensar en la ejecución sumaria, pero Platón formula (909b-d) una estrategia mucho más flexible:

- Prisión de por vida en una casa de readaptación diferente, que estará situada en un lugar totalmente aislado en las montañas o en el bosque, a la que se le dará el nombre de timoria ("casa de castigo": cf. 908a).

- Prohibición de toda relación con sus conciudadanos.

- Alimentación confiada a esclavos (para limitar ulteriores relaciones con los otros y las oportunidades de efectuar intercambios: además de lo estrictamente necesario, podemos imaginar que estos esclavos no tendrán ni la autorización ni la posibilidad de pasar ningún tiempo con los detenidos y que, en igual forma, un mínimo de diseminación de ideas "nefastas" entre ellos no podría producir efectos significativos a causa del control ideológico ejercido por sus amos).

- A su muerte, los cuerpos deberán ser abandonados más allá de las fronteras y dejados sin sepultura. Si, no obstante, un hombre libre le diera sepultura, cualquiera podrá acusarlo de impiedad (la inferencia es: si es un esclavo quien lo hace, no se aplica ninguna medida).

En cuanto a los hijos del condenado, serán considerados, de inmediato, huérfanos y tratados como tales, con las medidas de tutela previstas para otro tipo de huérfanos ( $c f$. XI 924a-925c), pero a condición de ser reconocidos útiles para la polis, es decir, capaces de convertirse en personas normales (por ejemplo a causa de su buena salud, o a causa de su patrimonio: si se tratara, pues, de niños más o menos discapacitados o sin patrimonio, el Estado hubiera podido negarles toda protección o tutela).

Hay que observar la atención para dar a conocer antes cuán temible será la condición del ateo activo, ya sea por lo que le concierna directamente o por el destino reservado a sus hijos.

Tercera tipología: formas de la superstición religiosa, modalidades anómalas como la edificación de pequeños santuarios privados para realizar los 
sacrificios o bien como la credulidad relativa a visiones y pesadillas (909d 910d). El peligro, nos explica Platón, está en dar origen a ritos clandestinos acompañados de formas anómalas de temor o de ilusión con respecto de los dioses (entre otras, la ilusión humana de poder ponerse de acuerdo con ellos y de lograr así ser felices, gracias a lo que cada uno hace en su casa en el transcurso de estos ritos) y generar desinterés por la religiosidad pública y legal. El nacimiento de una secta, por ejemplo, amenaza la estabilidad del contexto ideológico oficial, pero al mismo tiempo corre el riesgo de producir la insatisfacción de los dioses con respecto a la ciudad en su conjunto.

Para esta eventualidad, Platón plantea dos hipótesis. Si no se trata de un asunto grave, los nomophylakes ("guardianes de la ley") se limitarán a ordenar que los objetos de estos cultos privados sean transferidos a un lugar público y queden con ello eliminados del ámbito doméstico. Si hubiera resistencia, entonces se impondría multa e incautación de esos objetos. Si, por el contrario, se trata de un hecho más grave (como la edificación de verdaderos altares en el interior de una casa o en un lugar público, que implicaría el riesgo de provocar la falsa creencia de cualquiera de encontrarse en un santuario en apariencia del todo regular, en medio de otros), entonces se aplicaría la pena de muerte.

$$
* * *
$$

He aquí lo esencial. Observemos ante todo que Platón no amenaza con la pena de muerte sino en los casos de delitos muy cercanos a la impiedad. Con este propósito, compárense los pasajes siguientes: v 735de, depuración de los peores criminales que lleguen a la nueva colonia; Ix 854e, medidas para los casos más graves de robo sacrílego; Ix 856b: medidas contra el intento de trastornar la constitución de la ciudad con violencia; IX 860b: medidas contra el robo de lo que se encuentra dentro de los templos y/o contra quien manifieste ser enemigo de las leyes de la ciudad; IX 862c, medidas en caso de reincidencia; IX $881 \mathrm{~d}$, medidas contra el ciudadano proscrito de la ciudad, quien, habiéndose atrevido a entrar en los lugares sagrados, y habiendo sido castigado por este hecho, a pesar de ello, se atreve a hacerlo por segunda vez. La eliminación física es concebida, pues, como último recurso para asegurar la supervivencia de los principios fundamentales de la vida en sociedad, ya sea que la amenaza se traduzca en acciones objetivamente peligrosas, ya sea que se traduzca - aunque más bien diríamos: sobre todo si se traduce- en el intento de trastornar las premisas ideológicas.

En este punto, Platón muestra una gran moderación para su época: por ejemplo, no siente la necesidad de prever la pena de muerte para los esclavos o extranjeros, ni aquí ni en otros lugares. Si se aleja de la costumbre a este 
respecto, por el contrario comparte un verdadero aspecto honorable de la Grecia clásica: se abstiene de considerar toda hipótesis de sanción sádica o de tortura (si no es la tortura ritual de los esclavos: regresaré sobre este punto) u otras formas de castigo que puedan ser consideradas peores que la muerte. Sobre este asunto no solamente faltan pruebas de lo contrario durante un muy amplio periodo, ${ }^{5}$ sino que se observa también la ausencia de una ley para prohibir manifestaciones de crueldad, entre otras instancias, en las ejecuciones, lo cual es muy significativo.

En efecto, los ejemplos máximos de crueldad que conoció la época fueron las ejecuciones en masa durante la guerra y sobre todo, en la guerra civil, cuando se cerraron las puertas de un determinado lugar para dar muerte a aquellos que quedaban en su interior (varios ejemplos en Tucídides, entre otros, III 81.4-5). Pero podremos observar que en Atenas, en un caso de esta naturaleza, y tratándose de un lugar sagrado, los guardianes se preocupaban por hacer salir a los detenidos antes de matarlos (Tucídides I 126.11) y que los éforos de Esparta, habiendo bloqueado al rey Pausanias en un pequeño lugar contiguo a un templo, por temor de impiedad, antes que nada ordenaron quitar al techo del edificio y enseguida, cuando Pausanias estaba ya próximo a la muerte, lo hicieron salir, de suerte que expiró justamente después (Tucídides I 134.2).

El mismo Tucídides refiere -y como algo excesivo- el hecho de que unos tracios (es decir, unos no griegos), una vez ocupada la ciudad de Micalesos (al norte de Atenas y al este de Tebas), dieron muerte a casi todo el mundo, incluyendo a mujeres, ancianos y niños (en particular a los niños capturados en una escuela, llegando, en esta ocasión, al grado de hacer pedazos sus cuerpos), y agrega que se trataba de un población de actitud bárbara (homoia tou barbarikou) y ávida de sangre (phoinikotaton, ávida del rojo fenicio). El aspecto sorprendente del pasaje (VII 29.4-5) es que se trata justamente de un caso extremo, tanto a los ojos del historiador como en comparación con el conjunto de las evidencias de crueldades y maltratos.

$\mathrm{Y}$, por otra parte, la misma tortura de los esclavos llamados a dar testimonio delante de los jueces era, si no una formalidad, al menos una acción algo formal, dado que su función real no era sólo reemplazar el juramento de los libres (un esclavo no podría jurar), sino protegerlos contra el riesgo de ser castigados de nueva cuenta por parte de su amo, es decir, ponerlos en condiciones de hacer creer que la violencia física los había forzado por completo a relatar los hechos de los que, por desgracia, habían sido testigos directos,

${ }^{5}$ El empeoramiento de la costumbre griega a este respecto fue, según parece, muy gradual, esencialmente después de la ocupación romana. No conozco estudios sobre este punto, cuya importancia merecería, no obstante, mucha atención. 
sin poder insistir en enunciados falsos (como lo habrían hecho de muy buena gana para ayudar a su amo). Es evidente, por otro lado, que la muerte decretada contra los ateos no podía ser sino una ejecución sin el más mínimo sadismo. De otra manera habría habido impiedad en la ejecución misma.

Sobre este punto faltan por señalar dos detalles más:

- Primero, Platón no siente la necesidad de prohibir la crueldad extrema contra el condenado, ni aquí ni en otros pasajes (debe pensar, cosa que es notable, que no hay razón para prever delitos de esta naturaleza).

- Segundo, en un pasaje del libro IX (881ab), cuando escribe que la muerte no es la medida más extrema (thanatos ouk estin eschaton), agrega, por un lado, que la mitología registra castigos más severos en el Hades (sin precisarlos) y que, en el caso del parricidio, hay que inventar sanciones tan extremas como aquellas que están vigentes en el Hades. Pero, a continuación, habla de sanciones sobre todo vergonzosas, como el exilio, así como de otras, ya fueran positivas o negativas, para extranjeros y esclavos. Por tanto, nada que fuera realmente terrible.

Por lo que concierne al ateísmo, la impiedad, los ritos clandestinos y las sectas, no hay duda alguna de que Platón adoptó mucha más severidad que sus compatriotas, pues en Atenas hubo, sin duda, procesos de carácter ideológico contra filósofos sospechosos de ateísmo (Protágoras, Anaxágoras y Diágoras, además de Sócrates), pero no sin la intención de dañar a un partido político (Pericles en los dos primeros casos, los oligarcas en el caso de Sócrates) y no sin tolerar las manifestaciones de ateísmo en los escenarios (fueron espectaculares los casos de las Nubes de Aristófanes y del Belerofonte de Eurípides), o la invención ocasional (y nada seria) de otras divinidades como "Rencor" o "Buena Legislación", y hasta "Desvergüenza" y "Rebelión" (ver en particular Demóstenes XXV 34-35 y 52). ${ }^{6}$ De igual forma, la existencia de sectas religiosas o cultos particulares no planteaba verdaderos problemas, pues era una práctica común y corriente: además de los misterios, traeremos a colación el hecho de que incluso la Academia platónica era, desde el punto de vista formal, una especie de pequeña asociación consagrada en especial al culto de las musas.

Pero, precisamente para contrastar iniciativas de este género - en las cuales el anciano Platón veía formas de una actitud de relajamiento ideológico con la finalidad de legitimar ( $y$, por lo tanto, fomentar) toda forma de actitud de relajamiento práctico- nuestro filósofo consideró el delito religioso casi el único que merecía la pena capital.

Si, por otro lado, llega a considerar el delito religioso como el peor de los delitos que se pueden temer, de tal manera que el ateísmo sería el único

${ }^{6}$ Cf. K. J. Dover, Greek Popular Morality. Oxford, Blackwell's, 1974, pp. 141-144. 
crimen en verdad "innombrable" que se puede prever, entonces este hecho no subraya únicamente el alejamiento con respecto a nuestras actitudes comunes y corrientes (pensar que el delito puramente ideológico no puede pasar por un delito extremo - los criminalistas conocen no pocos delitos mucho más horrendos- o que a menudo la sociedad moderna pudo considerarlo incluso como un valor). El hecho mismo de que, por lo menos a los ojos de Platón, el delito de impiedad podía figurar entre las peores cosas de la vida comunitaria de su época, significa entonces que él debió conocer una sociedad donde había en realidad pocos excesos. Pues, a menos que se piense en una suerte de obcecación colectiva capaz de hacer que los peores excesos no se perciban, o en una reticencia capaz de empujarnos a hacernos ilusiones a este respecto, sigue estando verdaderamente fuera de toda duda el hecho de que la sociedad griega de su época no conoció formas de crueldad extrema. La misma obra de Platón sirve como prueba de este hecho, dado que él tiene tendencia a no ser indulgente hacia su presente y a ser severo en sus prescripciones (y, por otro lado, Tucídides no duda en subrayar los excesos de los que tiene noticia).

Esto significa que la Atenas clásica, a pesar de ciertas modas de estos últimos años que nos han animado a observarla como una sociedad eminentemente esclavista y consagrada a la explotación de las demás ciudades, es decir, como una organización profundamente parasitaria, debió tener un estándar de vida comunitaria que podemos todavía admirar con franqueza. La "dulzura de la vida" (tema de un hermoso libro de la señora Jacqueline de Romilly), ${ }^{7}$ debió haber tenido un sentido bastante concreto en un medio como ése, aunque fuera por comparación.

Hay que añadir que Platón, aún sin referirse de manera explícita a Tucídides, parece tener en cuenta el maravilloso capítulo 45 del libro tercero de sus Historias sobre la ineficacia de la pena capital. En efecto, nuestro filósofo prefiere sanciones dotadas de un claro valor simbólico, y en consecuencia no ve en la pena capital una venganza del Estado, sino una medida profiláctica extrema, frente al riesgo de una propaganda ideológica que vaya contra el "corazón" del sistema y a condición de que otras medidas resulten ser dramáticamente inadecuadas. Nada que ver, por lo tanto, con la idea de una proporción casi matemática entre la gravedad del delito y la gravedad de la sanción correspondiente.

${ }^{7}$ Cf. Jacqueline de Romilly, La douceur dans la pensée grecque. París, Belles Lettres, 1995. También son significativas, a este respecto, las investigaciones de Mariateresa Galaz; $c f$., en especial, "La protección social en la Atenas clásica", en Crónica Legislativa. Órgano de información, LvI legislatura. México, H. Cámara de Diputados, Año v, Nueva época, núm. 6, diciembre 1995-enero 1996, pp. 9-15. 
Finalmente, en lo que concierne a las prisiones, debe señalarse que Platón introduce dos tipos de centros de readaptación además de la prisión, lo cual, repito, constituye una excepción con respecto a la costumbre de amenazar, en los casos más graves, con la muerte o el exilio, de tal suerte que la detención estuviera limitada a periodos cortos. La idea de establecer prisiones permanentes para utilizarlas como una forma de castigo, se inscribe, pues, en la actitud de la sociedad de su tiempo de buscar de buena gana modalidades cada vez mas complejas -y costosas- de organización del Estado. ${ }^{8}$ Por lo demás, en la época en que Platón se entregó a la redacción de sus Leyes, en Atenas se pudo imaginar $-\mathrm{y}$ luego realizar y utilizar- un portento de complejidad y genialidad como es el kléroterion para el sorteo de los jueces populares de la Heliaia (Aristóteles, Ath. Pol. 64).

${ }^{8}$ Más sobre este punto en mi artículo "Il ricorso alla pena detentiva nelle Leggi di Platone", en O. Diliberto, ed., Il problema della pena criminale tra filosofia greca e diritto romano. Nápoles, Jovene, 1993 (Studi Economico-Giuridici LIV), pp. 347-369. 